\title{
ECO-INNOVATION BY ANTICIPATORY FAILURE DETERMINATION (AFD) METHOD
}

\author{
Chen, Jahau Lewis; Hung, Chuan-Jr \\ National Cheng Kung University
}

\begin{abstract}
This paper presents an eco-innovation method by revised the "Anticipatory Failure Determination (AFD)" method which is the failure analysis tools in TRIZ theory. Using the functional analysis to list the system process and make the functional analysis model. Based on the environmental efficiency factors and functional analysis model, Substance-Field inverse analysis can find a lot of failure modes in the system. In order to assess the priority of risk improvement, the designer can calculate the environmental risk priority number including controlling documents, public image and environmental consequences. Designer can quickly find out the potential failure mode in the complex engineering system with the systematic steps. The TRIZ methods are used for finding eco-innovation idea to solve failure problem. The capability of the whole eco-innovative design process was illustrated by the electrical motorcycle case.
\end{abstract}

Keywords: Ecodesign, Innovation, Sustainability, TRIZ, AFD

\section{Contact:}

Chen, Jahau Lewis

National Cheng Kung University

Mechanical Engineering

Taiwan

jlchen@mail.ncku.edu.tw

Cite this article: Chen, J.L., Hung, C. (2019) 'Eco-Innovation by Anticipatory Failure Determination (AFD) Method', in Proceedings of the 22nd International Conference on Engineering Design (ICED19), Delft, The Netherlands, 5-8 August 2019. DOI:10.1017/dsi.2019.334 


\section{INTRODUCTION}

Nowadays, many countries formulate policy to evaluate the green product. However, with the development of technology, new products or system begin multifunctional and complicated. When the product has serious failure, some results of environmental hazards happen. The traditional risk analysis becomes more difficult to apply to product now.

The AFD method was proposed by Ideation International Inc. (Kaplan et al., 2005) based on the subversion analysis in the 1990's. The AFD method has two different ways including the Failure Analysis (AFD-1) and the Failure Prediction (AFD-2). Ungvari (1999) describes the traditional failure analysis tool FMEA has several drawbacks. The user of FMEA may fall into the effect of psychological inertia. He proposes to use AFD method to find solution of failure problem effectively. Sunday (2014) integrates the axiomatic design method with AFD to solve failure problems. Wang and Qiu (2014) presented using AFD-1 method to find the failure condition of electrical motorcycle. Russo et al. (2016) used function analysis diagram to identify the failure event of crane system. The ideas of using TRIZ method for eco-innovative design tasks have been proposed since 2000 (Jones and, Harrison, 2000; Chen and Liu, 2001; Chang, Chen, 2003; Chen and Yang, 2011, Yang and Chen, 2011, Chen and Chen, 2014). Lindahl (Lindahl et al., 2000; Lindahl and Tingstrom, 2001) proposed environmental priority number (EPN) in environmental effect analysis (EEA) method.

In this study, the eco-innovation algorithm is based on AFD-2 and combined with functional analysis and Substance-Field inverse analysis method to improve AFD-2 functionality. In order to assess the priority of risk improvement, designer can calculate the environmental risk priority number including controlling documents, public image and environmental consequences. Designer can quickly find out the potential failure mode in the complex engineering system and perform eco-innovation task.

\section{ANTICIPATORY FAILURE DETERMINATION (AFD) METHOD}

The Anticipatory Failure Determination (AFD) method (Kaplan et al., 2005)is an application of TRIZ to risk analysis. AFD is particularly suitable to a class of scenarios of current importance, namely, those involving human error, sabotage, terrorism, and such. It is suggested that the AFD approach can be used to codify and organize the world's accumulated experience in the operation of plants and systems of various types, and to make this knowledge readily available to new designers. Furthermore, this can be done in such a way that the mistakes, accidents, and oversights of the past need not be repeated before the appropriate lessons are learned and become routine parts of engineering culture.

AFD-2 algorithm (Kaplan et al., 2005) is shown as follows:

Step 1: Formulate the original problem.

Step 2: Identify the success scenario.

Step 3: Formulate the inverted problem.

Step 4: Apparent ways to deteriorate the system function.

Step 5: Identify available resources.

Step 6: Utilize the knowledge base.

Step 7: Invent new solutions.

Step 8: Intensify and mask harmful effects.

Step 9: Analyze the revealed harmful effects.

Step 10: Prevent/eliminate the harmful effects.

\section{SUBSTANCE-FIELD INVERSE ANALYSIS METHOD}

The standard techniques of TRIZ 76 Standard Solutions are a further development of the standard solutions. One group of these contains six techniques for directly eliminating the effect of a harmful action (Ruhe, 2003), as shown in Table 1. Each of these techniques presents a substance-field solution model (Savransky, 2000) for one case of harmful energy transfer producing a harmful function. The standard solution tools of TRIZ may be used to generate innovative solution concepts.

One of TRIZ inventive principle "other way around" is used here to invert problem statements and solution techniques for failure anticipation. One way is simply to invert the objective. Therefore, a harmful function is treated as useful. The objective then is to magnify that harmful function, its effects and to invent new harmful functions. 
Table 1. 76 standard solutions for eliminating the effect of a harmful action technology (Ruhe, 2003)

\begin{tabular}{|c|c|}
\hline $\begin{array}{l}\text { Harmful action substance-field } \\
\text { model (There is a harmful } \\
\text { action on object S1) }\end{array}$ & $\mathrm{S}_{2}^{\mathrm{F}} \curvearrowright \mathrm{S}_{1}$ \\
\hline \multicolumn{2}{|c|}{ Substance-Field Model - Direct eliminating the effect of a harmful action technology } \\
\hline $\begin{array}{l}\text { Eliminating the effect of a } \\
\text { harmful action model }\end{array}$ & Meaning \\
\hline 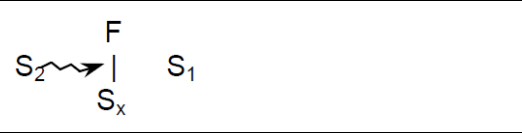 & Insulate $\mathrm{S} 1$ from the harmful action by substance-insulator $\mathrm{Sx}$ \\
\hline $\mathrm{S}_{2} \overbrace{F_{x}}^{F} \sim S_{1}$ & Counteract the harmful action with the opposing field Fx \\
\hline$S_{2} Z_{S_{x}} S_{1}$ & $\begin{array}{l}\text { Protect } S 1 \text { from the harmful action by a safety substance } S x \\
\text { that attracts the action to itself }\end{array}$ \\
\hline $\begin{array}{lll}S_{2}^{\prime} & F & S_{1}\end{array}$ & $\begin{array}{l}\text { Modify the source } \mathrm{S} 2 \text { of the action to turn off the harmful } \\
\text { action }\end{array}$ \\
\hline$S_{2} \sim \mathrm{F}_{\mathrm{X}}^{\mathrm{F}} \mathrm{S}_{1}$ & Modify S1 to be insensitive to the harmful action \\
\hline$S_{2} \sim S_{S_{1}}$ & $\begin{array}{l}\text { Alter amount of the zone of action, its duration or both to } \\
\text { decrease or completely eliminate the harmful action. }\end{array}$ \\
\hline
\end{tabular}

Another method is to invert some of the TRIZ tools (Ruhe, 2003). The method used here inverts a set of standard techniques by replacing harmful effects with useful effects, as shown in Table 2.

Table 2. Method of substance-field inverse analysis for eliminating useful action (Ruhe, 2003)

\begin{tabular}{|c|c|}
\hline $\begin{array}{l}\text { Useful action substance-field } \\
\text { model (There is a useful action } \\
\text { on object } \mathrm{S} 1 \text { ) }\end{array}$ & $\mathrm{S}_{2} \stackrel{\mathrm{F}}{\longrightarrow} \mathrm{S}_{1}$ \\
\hline \multicolumn{2}{|c|}{ Substance-Field Inverse Model - Method for eliminating the effect of a useful action } \\
\hline $\begin{array}{l}\text { Eliminating the effect of a } \\
\text { useful action model }\end{array}$ & Meaning \\
\hline$S_{2} \underset{S_{x}}{\stackrel{F}{\mid}} S_{1}$ & Insulate $\mathrm{S} 1$ from the useful action by substance-insulator $\mathrm{Sx}$ \\
\hline$S_{2} \frac{F}{F-r}$ & Counteract the useful action with the opposing field Fx \\
\hline$S_{2} S_{S_{x}} S_{1}$ & $\begin{array}{l}\text { Protect } \mathrm{S} 1 \text { from the useful action by a safety substance } \mathrm{Sx} \text { that } \\
\text { attracts the action to itself }\end{array}$ \\
\hline$S_{2} \quad F \quad S_{1}$ & Modify the source $S 2$ of the action to turn off the useful action \\
\hline $\mathrm{S}_{2} \stackrel{\mathrm{F}}{\longrightarrow} \mathrm{S}_{1}$ & Modify S1 to be insensitive to the useful action \\
\hline$S_{2} \quad F$ & $\begin{array}{l}\text { Alter amount of the zone of action, its duration or both to } \\
\text { decrease or completely eliminate the useful action. }\end{array}$ \\
\hline
\end{tabular}


Each of these techniques presents a Substance-Field solution model (Savransky, 2000) for a way to reduce a useful function. In each, if the function is not completed, then a failure may occur. Using these inverted models, the problem now is to create situations for each case that will reduce or eliminate the useful action. That is, to invent failures, expecting them so they may be eliminated. However, the existing solution tools of TRIZ are all useful, being essentially designed to solve innovative problems.

\section{ENVIRONMENT RISK PRIORITY NUMBER}

This study presents seven elements that harm the environment by transforming seven Eco-efficiency elements which are proposed from World Business Council for Sustainable Development (WBCSD). Designer uses these seven elements that harm the environment create the fault mode. Resource analysis and Substance-Field inverse analysis can help designers to create the details of fault mode. User will create a lot of fault mode from previous step. Therefore, user must calculate the Environment Risk Priority Number (E-RPN) to fault events. The Environment Risk Priority Number (E-RPN) is a modification of environmental priority number (EPN) in environmental effect analysis (EEA) method (Lindahl et al., 2000; Lindahl and Tingstrom, 2001). The qualitative value of E-RPN can be computed with the following equation.

$$
\mathrm{E}-\mathrm{RPN}=(\mathrm{Sc}+\mathrm{I}+\mathrm{A}) \times \mathrm{O} \times \mathrm{D}
$$

Where Sc is controlling documents; $\mathrm{I}$ is public image; $\mathrm{A}$ is environmental consequences; $\mathrm{O}$ is occurrence; and $\mathrm{D}$ is detection.

The value of E-RPN will affect the order in which the fault events are processed. The higher E-RPN value represents the more harmful to the environment. Thus, designer should deal with this failure event quickly.

\section{ECO-INNOVATION ALGORITHM}

The innovation algorithm has five parts, such as (1) Build System Model, (2) Build Reverse Model, (3) Find Failure Mode, (4) Analyze the Revealed Failure Mode, and (5) Eliminate the Failure Mode. Designers are able to come out with solution through the eco-innovation algorithm shown in Figure 1. This study replaces AFD software knowledge base with the TRIZ tools. With basic TRIZ concept, designers can solve problem through this algorithm step by step.

In the first part, designer needs to analyze the system and to formulate the original problem, and then describe the purpose of system. Functional model of system can be built completely by using functional analysis.

In the second part, this method describes the stage of the success scenarios from functional model. The interaction between the two components represents a success stage. List the successes scenarios and explain their results. To build reverse model, designers need to express success stage reversely to understand the failure phase.

In the third part, designer uses seven elements that harm the environment to create the fault mode. According to AFD method, for any failure or drawback to occur spontaneously, all the necessary components must be present within the system or its nearby environment. Resource analysis is applied to search the complete available resources. Designer should apply available resources, simple fault mode and Substance-Field inverse analysis to create the complete failure mode.

In the fourth and fifth part, designer needs to calculate the E-RPN to fault events which are found from previous part. Designer should give priority to deal with the failure events which have higher E-RPN value. Substance-Field analysis is the final step to solve problem and come up with solution.

\section{EXAMPLE}

Electrical motorcycle problem is selected as example to demonstrate the capability of proposed ecoinnovation method. In Taiwan, the gas-powered motorcycle is one of source of air pollution problem in city. The electrical motorcycle is the solution of air pollution problem. However, the low battery power capacity and long charging time for battery are the chief drawback of current most electrical motorcycle. Furthermore, the carbon footprint of electrical motorcycle using electricity from current fossil fuels power plant is still high. Eco-innovation idea is required to solve above problems. Gogoro 
in Taiwan created a city-based network of battery swapping stations called the Gogoro Energy Network and designed a high performance electric scooter called the Gogoro Smartscooter.

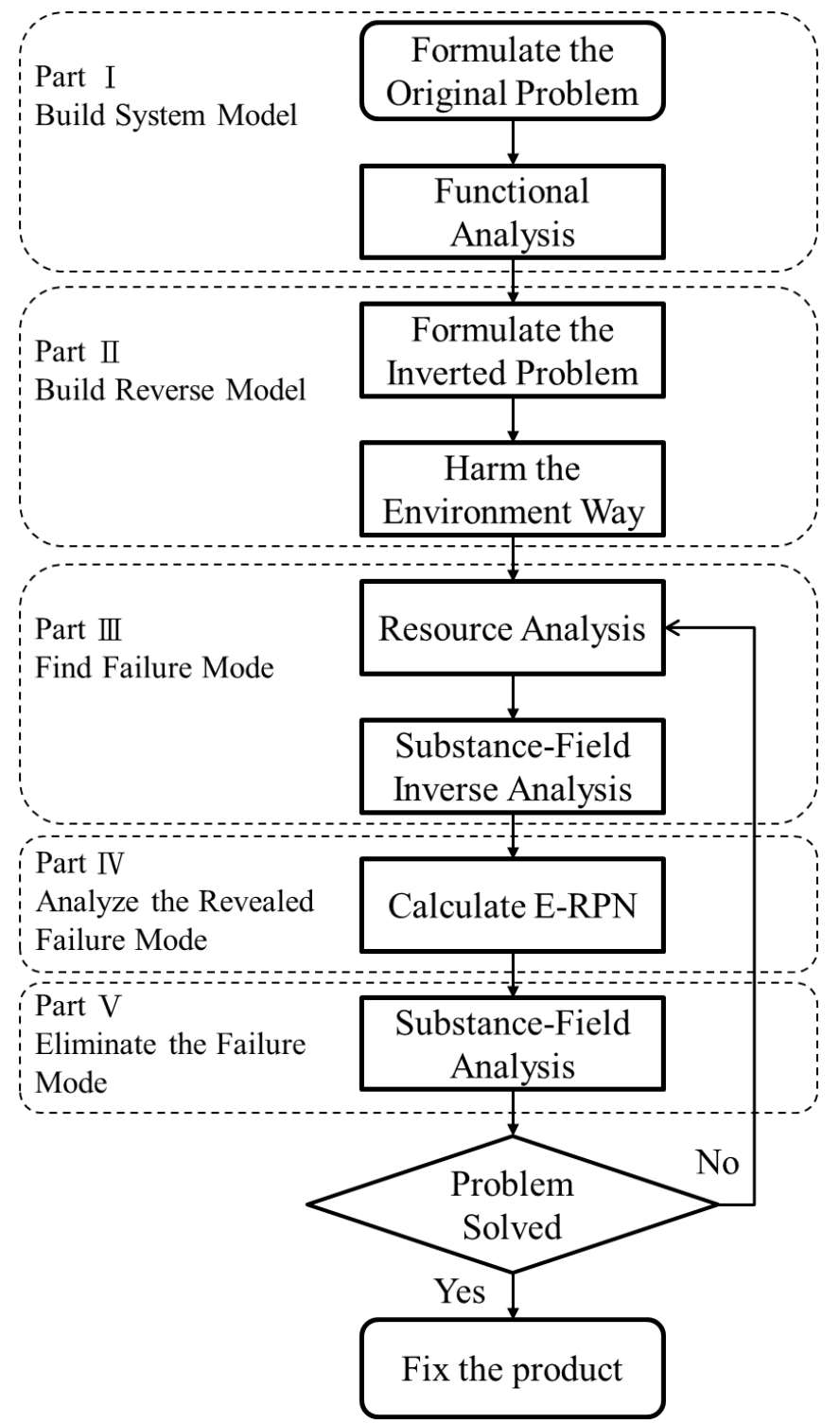

Figure 1. Eco-innovation design processBuild system model

This case is to evaluate the influences of environmental impact due to the failure mode of Gogoro battery swapping stations business system. Figure 2 shows the communication structure of Gogoro electrical motorcycle.

The purpose of this communication structure of Gogoro electrical motorcycle is to save contact exposure and to increase safety. Excluding the consultation function in mobile phone and start up function in motorcycle key, the function analysis model of Gogoro business system is expressed in Figure 3.

Based on the Gogoro business system function analysis model in Fig. 3, this method describes the stage of the success scenarios from functional model. The interaction between the two components represents a success stage. List the successes scenarios and explain their results, as shown in Table 3. 


\section{TOTALรSOLUTION}

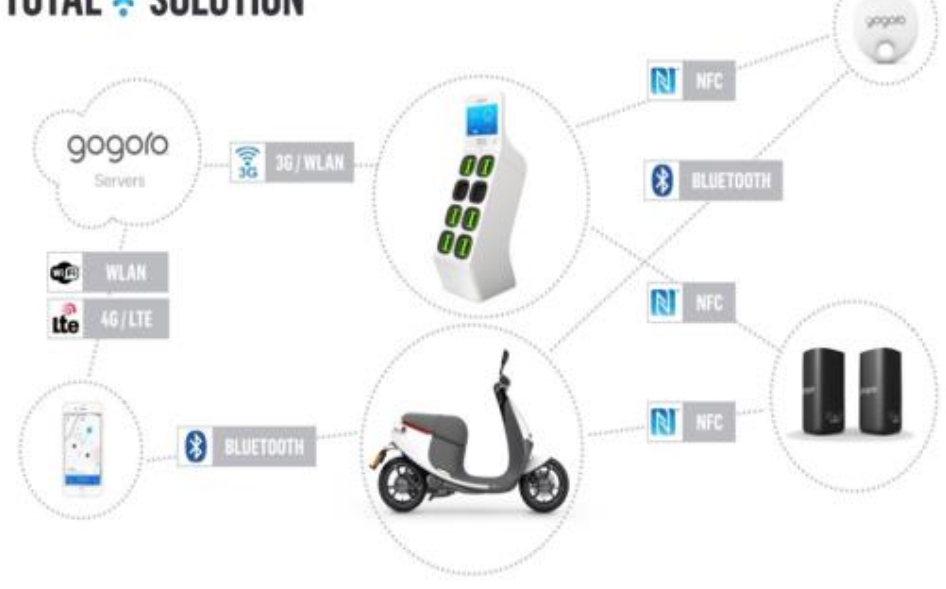

Figure 2. Gogoro communication system diagram (Gogoro, 2016)

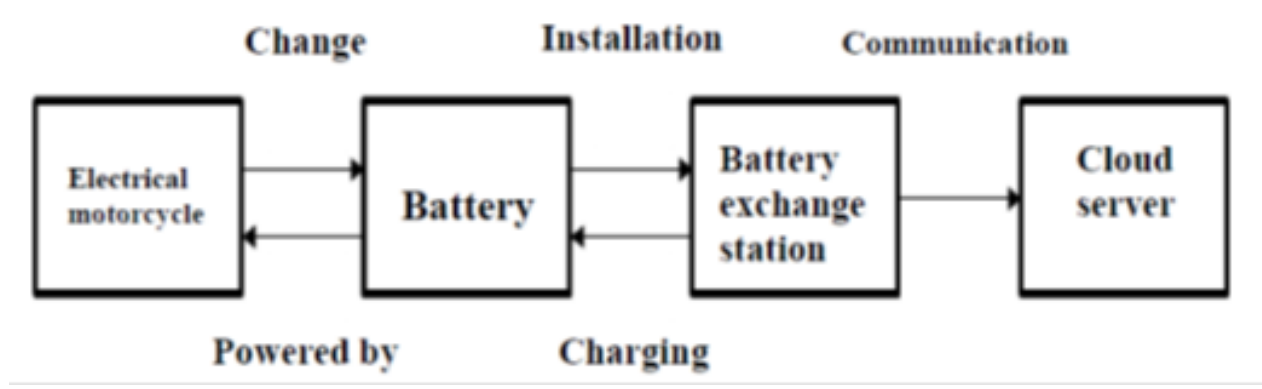

Figure 3. Gogoro business system function analysis model

\subsection{Build reverse model}

To build reverse model, designers need to express success stage reversely to understand the failure phase. The reverse success scenarios process of the Gogoro business system is expressed in Table 4. From Table 4, five failure stage processes are defined as initial events (IE1 to IE5). Violation of WBCSD seven eco-efficiency items is defined as seven final harmful effect states (HES), as shown in Table 5. The risk scenarios (RS) of the Gogoro business system is expressed in Table 6. It has 9 risk scenarios from RS1 to RS9.

\subsection{Find failure mode}

Designer can apply available resources, simple fault mode and Substance-Field inverse analysis to create the complete failure mode of Gogoro business system. The substance-field inverse analysis of IE3 (There is an exception on the installation) are shown in Table 7.

\subsection{Analyze the reversed failure mode}

The failure events of IE3 (There is an exception on the installation) are shown in Table 8. The E-RPN value of each event is calculated according to equation (1), as illustrated in Table 8.

\subsection{Eliminate the failure mode}

Based on E-RPN value in Table 8, the failure event "Battery exchange station is out of power" has the highest E-RPN value. This failure event needs to improve at first time. The substance-field model of this event is shown in Figure 4. The standard solution number 1.13 of TRIZ method "The system cannot be changed but a permanent or temporary additive is acceptable, but use a permanent or temporary external additive S3 to change either S1or S2." can be used as the innovation concepts for this event. 
Table 3. Success scenarios process

\begin{tabular}{|c|c|c|c|}
\hline Success Stage Process & Results & \multicolumn{2}{|c|}{ Function Analysis Model } \\
\hline $\begin{array}{l}\text { Motorcycle replacement } \\
\text { battery }\end{array}$ & $\begin{array}{l}\text { Energy-depleted batteries replaced with } \\
\text { batteries with abundant energy }\end{array}$ & Motorcycle & Battery \\
\hline \multirow[b]{2}{*}{$\begin{array}{l}\text { Battery powered to } \\
\text { motorcycle }\end{array}$} & \multirow[b]{2}{*}{ Motorcycle get power operation } & \multicolumn{2}{|c|}{ Powered by } \\
\hline & & Battery & Motorcycle \\
\hline \multirow[b]{2}{*}{$\begin{array}{l}\text { Battery installed on } \\
\text { battery exchange station } \\
\text { vacancy }\end{array}$} & \multirow[b]{2}{*}{$\begin{array}{l}\text { The battery exchange station reads the } \\
\text { battery information and prepares to } \\
\text { charge }\end{array}$} & \multicolumn{2}{|c|}{ Installation } \\
\hline & & Battery & $\begin{array}{l}\text { Battery } \\
\text { exchange } \\
\text { station }\end{array}$ \\
\hline \multirow[b]{2}{*}{$\begin{array}{l}\text { Battery charging station } \\
\text { is charging batteries }\end{array}$} & \multirow[b]{2}{*}{$\begin{array}{l}\text { The battery is powered by electricity to } \\
\text { supplement internal energy }\end{array}$} & \multicolumn{2}{|c|}{ Charging } \\
\hline & & $\begin{array}{l}\text { Battery } \\
\text { exchange } \\
\text { station }\end{array}$ & Battery \\
\hline \multirow[b]{2}{*}{$\begin{array}{l}\text { Battery exchange station } \\
\text { sends a signal to the } \\
\text { cloud server }\end{array}$} & \multirow[b]{2}{*}{$\begin{array}{l}\text { The cloud server reads the information } \\
\text { collected by the battery exchange station } \\
\text { and stores it in the database }\end{array}$} & \multicolumn{2}{|c|}{ Communication } \\
\hline & & $\begin{array}{l}\text { Battery } \\
\text { exchange } \\
\text { station }\end{array}$ & $\begin{array}{l}\text { Cloud } \\
\text { server }\end{array}$ \\
\hline
\end{tabular}

Table 4. Reverse success scenarios process

\begin{tabular}{|c|c|c|}
\hline Failure Stage Process & Function an & Model \\
\hline $\begin{array}{l}\text { IE1: Incorrect replacement } \\
\text { process }\end{array}$ & Motorcycle & Battery \\
\hline \multirow{3}{*}{ IE2: Poor power supply } & \multicolumn{2}{|c|}{ Powered by } \\
\hline & Battery & Motorcycle \\
\hline & & \\
\hline $\begin{array}{l}\text { IE3: There is an exception on } \\
\text { the installation }\end{array}$ & Battery & $\begin{array}{l}\text { Battery } \\
\text { exchange } \\
\text { station }\end{array}$ \\
\hline \multirow[b]{2}{*}{ IE4: Poor charging } & \multicolumn{2}{|c|}{ Charging } \\
\hline & $\begin{array}{l}\text { Battery } \\
\text { exchange } \\
\text { station }\end{array}$ & Battery \\
\hline \multirow[b]{2}{*}{ IE5: Communication error } & \multicolumn{2}{|c|}{ Communication } \\
\hline & $\begin{array}{l}\text { Battery } \\
\text { exchange } \\
\text { station }\end{array}$ & $\begin{array}{l}\text { Cloud } \\
\text { server }\end{array}$ \\
\hline
\end{tabular}


Table 5. Final harmful effect state

\begin{tabular}{|l|l|}
\hline Final harmful effect state & Description \\
\hline HES1 & Increase the material intensity of its goods and services \\
\hline HES2 & Increase the energy intensity of its goods and services \\
\hline HES3 & Increase the dispersion of any toxic materials \\
\hline HES4 & Reduce the recyclability of its materials \\
\hline HES5 & Reduce the sustainable use of renewable resources \\
\hline HES6 & Reduce the durability of its products \\
\hline HES7 & Reduce the service intensity of its goods and service. \\
\hline
\end{tabular}

Table 6. Risk Scenarios

\begin{tabular}{|l|l|l|l|}
\hline RS1. & IE1 $\rightarrow$ HES6 & RS6. & IE3 $\rightarrow$ HES7 \\
\cline { 2 - 4 } RS2. & IE1 $\rightarrow$ HES7 & RS7. & IE4 $\rightarrow$ HES2 \\
\hline RS3. & IE2 $\rightarrow$ HES2 & RS8. & IE4 $\rightarrow$ HES7 \\
\hline RS4. & IE2 $\rightarrow$ HES7 & RS9. & IE5 $\rightarrow$ HES7 \\
\hline
\end{tabular}

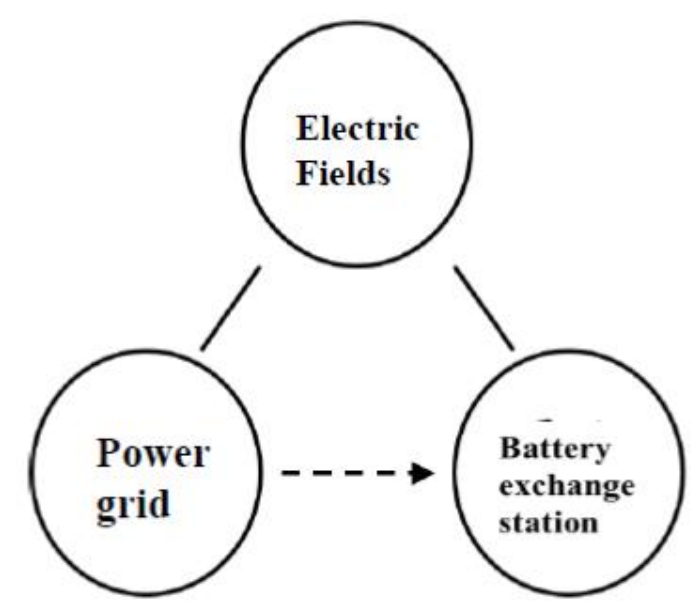

Figure 4. Failure event substance-field model

The battery swapping station can power by solar energy during battery exchange station is out of power, as shown in Figure 5. Solar power is green energy and it can be as power outage backup power during out of power in battery exchange station. Furthermore, solar power can be treated as second power supply source.

\section{CONCLUSIONS}

This paper integrates AFD-2 method, TRIZ theory, Eco-efficiency elements, and green assessment to establish a systematic and innovative process to assist designers searching and solving potential risks in engineering system. The failure modes of system were found by AFD-2 method with substancefield inverse analysis technique. The Environment Risk Priority Number (E-RPN) of fault events is used to evaluate the environmental impact of failure mode. The TRIZ methods are used for finding eco-innovation idea to solve failure problem. The capability of the whole eco-innovative design process was demonstrated by the electrical motorcycle case. 
Table 7. IE3 substance-field inverse analysis

\begin{tabular}{|c|c|c|}
\hline \multicolumn{3}{|l|}{ Function Analysis } \\
\hline Failure Stage & \multicolumn{2}{|l|}{ IE3 : There is an exception on the installation } \\
\hline \multicolumn{3}{|l|}{ Sub-Field Model } \\
\hline \multicolumn{3}{|c|}{ Substance-Field Inverse Analysis } \\
\hline Failure Model & Failure Mode & $\begin{array}{l}\text { Risk } \\
\text { Scenarios }\end{array}$ \\
\hline \multirow{2}{*}{$S_{2} \underset{S_{x}}{\longrightarrow} \quad S_{1}$} & $\begin{array}{l}\text { The battery is not properly placed and does not touch } \\
\text { the battery exchange terminal. }\end{array}$ & RS6 \\
\hline & $\begin{array}{l}\text { Foreign material in the battery compartment of the } \\
\text { exchange station interference the NFC device } \\
\text { verification. }\end{array}$ & RS6 \\
\hline \multirow{2}{*}{$\mathrm{S}_{2} \underset{\mathrm{r}}{\stackrel{\mathrm{F}}{\longrightarrow}} \mathrm{S}_{1}$} & $\begin{array}{l}\text { Temperature affects terminal tolerance, damage } \\
\text { placed terminal. }\end{array}$ & RS5 \\
\hline & $\begin{array}{l}\text { Electromagnetic interference battery NFC device } \\
\text { verification. }\end{array}$ & RS6 \\
\hline \multicolumn{3}{|l|}{$S_{2} F_{\quad} S_{1}$} \\
\hline $\mathrm{S}_{\mathrm{x}}$ & & \\
\hline$S_{2}^{\prime} \quad F \quad S_{1}$ & $\begin{array}{l}\text { Battery NFC device is abnormal and cannot be } \\
\text { verified. }\end{array}$ & RS6 \\
\hline \multirow{4}{*}{$\mathrm{S}_{2} \stackrel{\mathrm{F}}{\longrightarrow} \mathrm{S}_{1}^{\prime}$} & $\begin{array}{l}\text { Battery exchange station is out of power and cannot } \\
\text { be placed. }\end{array}$ & RS6 \\
\hline & $\begin{array}{l}\text { Battery exchange system is wrong and cannot be } \\
\text { placed. }\end{array}$ & RS6 \\
\hline & $\begin{array}{l}\text { Battery exchange station mechanism is destroyed and } \\
\text { damage occurs for placing the battery. }\end{array}$ & RS5 \\
\hline & $\begin{array}{l}\text { Battery exchange station NFC device is abnormal and } \\
\text { cannot be verified. }\end{array}$ & RS6 \\
\hline \multirow{2}{*}{$\begin{array}{lll} & F & \\
S_{2} & & S_{1}^{\prime}\end{array}$} & & \\
\hline & & \\
\hline
\end{tabular}

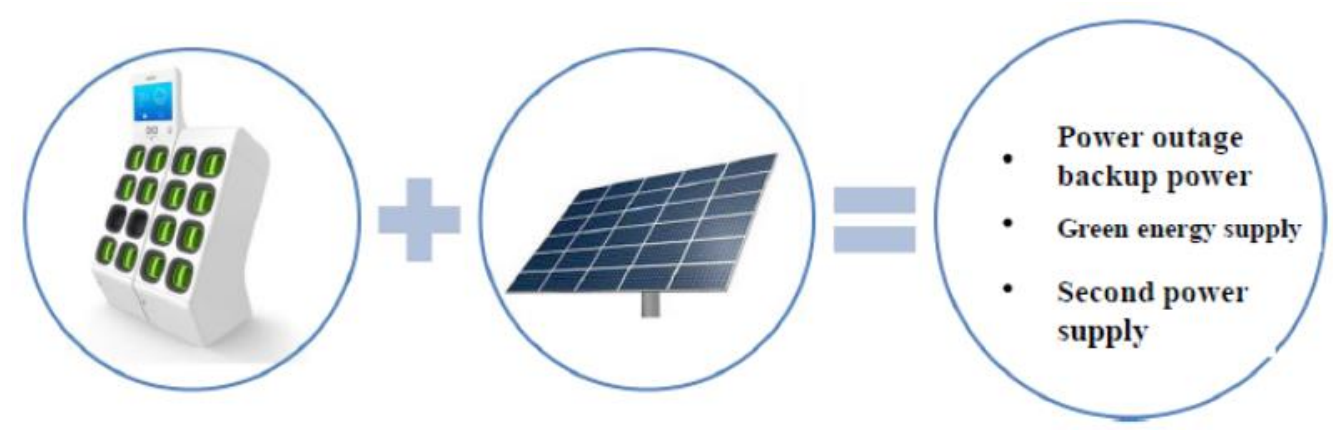

Figure 5. Eco-innovation concept 
Table 8. Failure event evaluation

\begin{tabular}{|c|c|c|c|c|c|c|c|c|}
\hline Stage & Failure event & Sc & I & A & EPN & $\mathrm{O}$ & $\mathrm{D}$ & E-RPN \\
\hline \multirow{9}{*}{ IE3 } & $\begin{array}{l}\text { The battery does not touch the battery } \\
\text { exchange terminal. }\end{array}$ & 1 & 1 & 1 & 3 & 5 & 3 & 45 \\
\hline & $\begin{array}{l}\text { Foreign material interference the NFC } \\
\text { device verification }\end{array}$ & 1 & 2 & 1 & 4 & 4 & 5 & 80 \\
\hline & Temperature affects terminal tolerance & 1 & 1 & 2 & 4 & 5 & 4 & 80 \\
\hline & $\begin{array}{l}\text { Electromagnetic interference battery } \\
\text { NFC device verification }\end{array}$ & 1 & 2 & 1 & 4 & 3 & 7 & 84 \\
\hline & Battery NFC device is abnormal & 1 & 2 & 1 & 4 & 4 & 3 & 48 \\
\hline & $\begin{array}{l}\text { Battery exchange station is out of } \\
\text { power }\end{array}$ & 2 & 3 & 1 & 6 & 4 & 8 & 192 \\
\hline & Battery exchange system is wrong & 1 & 2 & 1 & 4 & 4 & 6 & 96 \\
\hline & $\begin{array}{l}\text { Battery exchange station mechanism is } \\
\text { destroyed }\end{array}$ & 1 & 2 & 2 & 5 & 4 & 6 & 120 \\
\hline & $\begin{array}{l}\text { Battery exchange station NFC device } \\
\text { is abnormal }\end{array}$ & 1 & 2 & 1 & 4 & 4 & 3 & 48 \\
\hline
\end{tabular}

\section{REFERENCES}

Chang, H. and Chen, J. (2003), "The conflict-problem-solving CAD software integrating TRIZ into ecoinnovation", Journal of the Advance in Engineering Software, Vol. 35, pp. 553-566.

Chen, J. and Liu, C. (2001), "An Eco-Innovative Design Approach Incorporating the TRIZ Method without Contradiction Analysis”, Journal of Sustainable Product Design, Vol. 1, No. 4, pp. 263-272.

Chen, J. and Yang, Y. (2011), "Eco-innovation by integrating biomimetic with TRIZ ideality and evolution rules", Globalized Solutions for Sustainability in Manufacturing, 18th CIRP International Conference on Life Cycle Engineering, Braunschweig, Germany, J., Hesselbach and C. Herrmann, Eds., Springer, pp. 101-106.

Chen, W. and Chen, J. (2014), "Eco-innovation by Integrating Biomimetic Design and ARIZ", Procedia CIRP, Vol. 15, pp. 401-406.

Gogoro. (2016), "Zero-thefts-of-gogoro”, Available at:https://www.gogoro.com/tw/press/releases/2016-10-19zero-thefts-of-gogoro/

Jones, E. and Harrison, D. (2000), "Investigating the Use of TRIZ in Eco-innovation”, The TRIZ Journal, Sep. Kaplan, S., Visnespolschi, S., Zlotin, B. and Zusman, A. (2005), New Tools for Failure and Risk Analysis: An Introduction to Anticipatory Failure Determination (AFD) and the Theory of Scenario Structuring. ISBN $1-928747-0-51$.

Lindahl, M., Tingstrom, J. and Jensen, C. (2000), “A Comparison between the Environmental Effect Analysis (EEA) and the Life Cycle Assessment (LCA) Methods - Based on Four Case Studies", Proceedings of the 7th International Seminar on Life Cycle Engineering, November 27-29, Tokyo, Japan.

Lindahl, M. and Tingstrom, J. (2001), A Small Textbook on Environmental Effect Analysis, Department of Technology University of Kalmar, Sweden.

Ruhe, T.W. (2003), “Anticipating Failures with Substance-Field Inversion”, TRIZ-Journal, Feb 2003, Available at: https://triz-journal.com/anticipating-failures-substance-field-inversion-triz-methods-case-study/.

Russo, D., Birolini, V. and Ceresoli, R. (2016), "FIT: a TRIZ based Failure Identification tool for ProductService Systems", Procedia CIRP, Vol. 47, pp. 210-215.

Savransky, S.D. (2000), Engineering of Creativity. CRC Press, U.S.

Sunday, E. (2014), Extension and Modication of Anticipatory Failure Determination Approach Based on I-TRIZ. University of Stavanger, Norway, June.

Ungvari, S. (1999), “The Anticipatory Failure Determination Fact Sheet”, TRIZ-Journal, Oct 1999, Available at: https://triz-journal.com/anticipatory-failure-determination-fact-sheet/

Wang, L. and Qiu, W. (2014), "E-Bike Head-Lamp Failure Analysis based-on Failure Anticipation Analysis", Applied Mechanics \& Materials, Vol. 668-669, pp. 916-919.

Yang, C. and Chen, J. (2011), “Accelerating Preliminary Eco-innovation Design for Products that Integrates Case-Based Reasoning and TRIZ method”, Journal of Cleaner Production, vol. 19, pp. 998-1006.

\section{ACKNOWLEDGMENTS}

This research is sponsored by the Ministry of Science and Technology, Taiwan, under Grant number: MOST 105-2621-M-006-009 \& MOST 106-2621-M-006-004. 